\title{
Late diagnosis of cryptorchidism: a failure of medical screening?
}

\author{
A Sarmah
}

\begin{abstract}
A retropective review of hospital and available community records of 47 children undergoing orchidopexy in a district hospital was undertaken to determine adequacy of screening for cryptorchidism and factors associated with late referral. Twenty eight of these boys were previously examined on 108 occasions. Diagnosis was missed on 32 occasions and the record of 38 clinical examinations did not include position of testes. In the case of $\mathbf{1 6}$ boys (four under school age and 12 of school age) appropriate action was not taken once the diagnosis was made. Diagnosis was reliably made in school aged children but in children under the age of 1 year cryptorchidism was frequently missed by the examining doctor. It is suggested that criteria for diagnosis and referral should be agreed in any surveillance programme. Junior doctors in hospital responsible for routine clinical examination of children during admission and clinical medical officers or general practitioners during routine clinical examination of boys should be clearly instructed to examine and record the position of the testes.
\end{abstract}

The testis arises from the germinal ridge on the posterior abdominal wall medial to the developing kidney, joins with the epididymis and vas deferens, and then descends into the scrotum. The testis lies at the iliac fossa at 3 months and within the inguinal canal at 7 months of intrauterine life. By 8 months it is entering the scrotum and by birth in the full term infant it should be in the scrotum. ${ }^{1}$

If for any reason the descent of the testis is arrested in its normal pathway, the condition is described as undescended testis. If the testis deviates from its normal course of descent the condition is called ectopic testis. In both conditions the testis is absent from the scrotal sac and this is usually described as cryptorchidism, which can be bilateral or unilateral.

The incidence of cryptorchidism is reported to be rising, ${ }^{3}$ and has recently been found to be $1.6 \%$ in boys at the age of 3 months. The incidence is higher at birth and higher still in preterm babies. ${ }^{2}$ It becomes significantly less by the age of 3 months, because in some babies the testis descends during the first three months of life.

Farnborough Hospital, Farnborough Common, Orpington, Kent BR6 8ND

Correspondence to: Dr Sarmah.

Accepted 4 February 1992 descend any further. In some cases a descended testis is found to be undescended again at a later age. ${ }^{4}$ This is usually where the testis is absent from the scrotal sac at birth and descends during the first three months of life. ${ }^{5}$
If a testis is left in its undescended or maldescended position for a prolonged period there are risks of atrophy, torsion, malignant changes, and subfertility. Atrophic changes have been described at 2 years. ${ }^{6}$ Therefore, it seems essential that cases of cryptorchidism are diagnosed early and treated early.

It has been suggested that the age of diagnosis of cryptorchidism in a district is an important measure of the effectiveness of the child health surveillance programme, and it should be one of the criteria to be used for auditing the service. ${ }^{78}$

\section{Subjects and methods}

All boys admitted for orchidopexy into the paediatric ward of a district general hospital during the year 1989 were included in this study. These children were admitted to the ward for orchidopexy after being seen by a member of the surgical team as an inpatient or as an outpatient.

The district hospital was located in a London suburban district with a population of 230000 of whom 40000 were under 15 years of age. The annual birth rate at the maternity hospital of the district was 3000 . The district child health surveillance programme made provision for all children to be examined by a clinical medical officer at the age of 6 weeks, 15-18 months, and at school entry.

All new entrants to local schools were offered a clinical examination by a doctor when there was no record of a medical examination at or around school age. Although the exact uptake of these examinations were not available, it could be assumed that $90 \%$ of the boys would have had at least one medical examination by a doctor within two years of school entry. Some 1700 clinical medical officer sessions were used for routine child health surveillance in the district in 1989.

In addition all newborn babies were routinely examined by a doctor within the first 24 hours of birth and again before discharge. Annually the paediatric department and casualty department of the hospital between them saw 15000 childhood cases (approximate average over the last few years).

\section{Results}

There were 47 admissions for orchidopexy. Hospital notes of all 47 boys were reviewed together with community child health notes of 33 boys; 14 children lived outside the borough, and their community records were not obtainable. Of the 47 boys, 13 had bilateral cryptorchidism and 16 had left sided cryptorchidism. 
The longest waiting time after referral was two years (except for the seven children diagnosed below the age of 3 years). However, only $17 \%$ of these were operated upon under the age of 5 years.

The following examples are specially listed to highlight some of the missed opportunities for early treatment and diagnosis.

(1) In the case of four boys the condition was diagnosed before the age of 4 years, but no action was taken.

(2) In 12 other boys diagnosis was made after the age of 5 years but they were called up for review before being referred to surgeons; two such boys missed review appointments and referral was delayed by more than one year.

(3) Of two boys who had orchidectomy, one was diagnosed at the age of 4 years but his parents refused referral to hospital until the age of 6 years, when he had a first stage orchidopexy but did not turn up for the second stage operation for a long time; at the time of operation the testis was atrophic and was excised. The other boy missed his initial call for operation and suffered from a torsion of the undescended testis before admission to hospital.

(4) Two boys with bilateral undescended testes underwent orchidopexy on one side but were not followed up and needed to be referred again to the surgeons.

(5) Two patients were admitted to a special care nursery in the neonatal period but the diagnosis was missed. The other patient, who had right sided orchidopexy at the age of 10 years, was surgically treated for congenital pyloric stenosis at the age of 6 weeks and was followed up for a suspected right sided inguinal hernia but was lost from follow up subsequently.

(6) One patient was diagnosed as having right sided undescended testis in the newborn period but the testis descended by 6 months of age and he was discharged from follow up. He underwent right sided orchidopexy at the age of 10 years.

Table 1 Age at orchidopexy/orchidectomy $(n=47)$

\begin{tabular}{llllllllrrr}
\hline Age (years) & 3 & 4 & 5 & 6 & 7 & 8 & 9 & 10 & 11 & 12 \\
No of boys & 1 & 7 & 7 & 3 & 7 & 7 & 3 & 7 & 1 & 4
\end{tabular}

Table 2 Recording in the notes of the position of testes after a clinical examination of doctors working in community child health, the paediatric department, and in other departments within the hospital

\begin{tabular}{|c|c|c|c|c|c|}
\hline \multirow{2}{*}{$\begin{array}{l}\text { Age at } \\
\text { examination }\end{array}$} & \multirow{2}{*}{$\begin{array}{l}\text { Group of } \\
\text { doctors: }\end{array}$} & \multirow{2}{*}{$\begin{array}{l}\text { No of } \\
\text { examinations }\end{array}$} & \multicolumn{3}{|c|}{ Position of testes } \\
\hline & & & Unrecorded & $\begin{array}{l}\text { Correctly } \\
\text { recorded }\end{array}$ & $\begin{array}{l}\text { Incorrectly } \\
\text { recorded }\end{array}$ \\
\hline $0-3$ months & $\begin{array}{l}\text { Community } \\
\text { Paediatrics } \\
\text { Others }\end{array}$ & $\begin{array}{r}18 \\
4 \\
1\end{array}$ & $\begin{array}{l}6 \\
2 \\
0\end{array}$ & $\begin{array}{l}3 \\
1 \\
0\end{array}$ & $\begin{array}{l}9 \\
1 \\
1\end{array}$ \\
\hline 3 months -4 years & $\begin{array}{l}\text { Community } \\
\text { Paediatrics } \\
\text { Others }\end{array}$ & $\begin{array}{r}20 \\
14 \\
3\end{array}$ & $\begin{array}{r}13 \\
6 \\
2\end{array}$ & $\begin{array}{l}1 \\
2 \\
1\end{array}$ & $\begin{array}{l}6 \\
6 \\
0\end{array}$ \\
\hline 4 years and over & $\begin{array}{l}\text { Community } \\
\text { Paediatrics } \\
\text { Others }\end{array}$ & $\begin{array}{r}33 \\
6 \\
9\end{array}$ & $\begin{array}{l}4 \\
1 \\
4\end{array}$ & $\begin{array}{r}24 \\
5 \\
1\end{array}$ & $\begin{array}{l}5 \\
0 \\
4\end{array}$ \\
\hline Total & & 108 & 38 & 38 & 32 \\
\hline
\end{tabular}

"Comunity=clinical medical officers/senior clinical medical offiers; paediatrics = senior and junior doctors of the paediatric departments; and others=senior and junior doctors working in other specialities within the hospital.
(7) One boy was seen repeatedly in a regional centre for developmental delay but undescended testis was missed. One patient was admitted to a children's hospital for bronchial asthma but undescended testis was not diagnosed.

The 47 boys referred to the surgery department included two under 1 year of age, referred from the maternity hospital, five aged 1-3 of whom three were referred by surgeons, one from a child health clinic, and one from the child development centre. The 40 children aged 4 or more included 19 referred from the child health clinics, 15 referred by general practitioners, and one each from the paediatric department, surgeons from another district, and from the accident and emergency department. In the remaining three the source of referral was unclear.

The number of boys referred by general practitioners included two boys diagnosed by their mother and a number who were diagnosed by clinical medical officers, but referred through their general practitioners. Of three boys referred by the surgeons themselves, diagnosis was made when two were admitted for circumcision and one for abdominal pain.

Table 1 summarises the age distribution of these boys. Age in this table was calculated in years at their last birthday before orchidopexy. Table 2 shows the number of times these children were examined before admission to hospital for orchidopexy. In this table only a general clinical examination done for the purpose of making a medical assessment was included. Examinations without an entry in the case notes indicating that an abdominal examination or a systematic examination was carried out were excluded.

Examinations of the same boy at different consultations were listed as separate examinations. The clinical examinations carried out by the community medical officer were done either as part of a routine surveillance check or as part of a consultation done for other symptoms. The clinical examinations carried out by hospital doctors included examinations done in outpatient clinics and in the ward. Most of these examinations were carried out by senior house officers, but a small number were undertaken by registrars or consultants.

\section{Discussion}

There were other district general hospitals and children's hospitals where children from the district might undergo orchidopexy. Similarly, children from neighbouring districts are admitted for orchidopexy and were included in this study.

The figures for orchidopexy in the hospital would not reflect the incidence of cryptorchidism in the district population. The neonatal notes could not be reviewed for three main reasons: (i) many boys were born outside the district, (ii) the common practice of recording findings of routine neonatal examination in maternal records, and (iii) frequent changes in name and address.

Although there is considerable doubt about 
the benefit of early surgery for cryptorchidism in preventing future malignancy and subfertility, social, psychological, and clincal factors favour early surgery. The recent trend has been to operate early. ${ }^{9} 10$ However, although most surgeons in a group of district hospitals favoured surgery below school age, only $32 \%$ of orchidopexies were done under 5 years. ${ }^{11}$ The average age at orchidopexy has been reported as 6 years ${ }^{1}$ and 7 years. ${ }^{10}$ The average age of surgery in this group of boys was rather higher with more than $50 \%$ of the boys 7 years or older. Only $17 \%$ of the children were of preschool age.

These results illustrated some causes for delay in surgery.

(1) Undescenced testis was frequently missed by doctors during the first year of life; this has been previously reported. ${ }^{12}$ The reasons for this were not clear. It could be that some incompletely descended testes lying in the upper part of the scrotum were wrongly diagnosed as completely descended. Simple clinical criteria have been shown to be as reliable as complicated measurements in detection of cryptorchidism. ${ }^{2}$ Failure of detection at an early age resulted in most boys being more than 5 years at the time of diagnosis.

(2) There was unnecessary delay in referral to surgeons once the diagnosis was made even when the child was over 5 years of age. This resulted from lack of clear guidelines to the screening doctors. This delay was recently highlighted in another paper. ${ }^{10}$

(3) Some boys could have been diagnosed by the hospital doctors if testes of all boys were routinely examined during medical assessment. Nineteen of the 47 boys were diagnosed at school medical examination suggesting a continuing value for routine medical examination at school entry. A selective screening procedure, as suggested recently, ${ }^{13}$ would probably result in further delay in diagnosis.

\section{CONCLUSION}

In general the diagnosis and management of cryptorchidism in this district has been far from satisfactory. Similar findings have been reported from other centres. To improve the diagnosis and management of cryptorchidism the following recommendations are made:

(1) Doctors and other health workers under- taking surveillance procedures should be adequately trained in the technique of examining testes of young babies and children.

(2) Routine surveillance examinations should include examination of male genitalia and recording the findings in the case record.

(3) Junior doctors in all departments dealing with children should be instructed to include examination of male genitalia in all routine medical examinations.

(4) Every district should have clear policies directing doctors to refer boys over 6 months with undescended testis to surgeons.

(5) Babies who are born with undescended testis should be seen at approximately 12 months, even if the testis appeared descended by the age of 6 months or so.

(6) Physical examination at or about the age of school entry remains an effective screening examination for cryptorchidism.

I am most grafeful to Dr AMB Golding and Professor BW Taylor for helping me in writing this paper.

1 Atwell JD. Everyday paediatric surgery. In: Hadfield J, Hobsley M, eds. Current surgical practice. Vol 3. London: Edward Arnold, 1981:170-96.

2 John Radcliffe Cryptorchidism Study Group. Clinical diagnosis of cryptorchidism. Arch Dis Child 1988;63:587-91.

3 Chilvers C, Pike MC, Foreman D, Fogelman K, Wadsworth ME. Apparent doubling of frequency of undescended testis ME. Apparent doubling of frequency of undescended

4 Atwell JD. Ascent of testis; fact or fiction. Br F Urol 1985;57: Atwell JDD.

5 John Radcliffe Hospital Cryptorchidism Study Group. Boys with late descending testis: the source of patients with retractile testis undergoing orchidopexy? $B M \mathcal{F} 1986 ; 293$ 789-90.

6 Kroorand RL, Perlmuther AD. Anomalies of testis. In: Behrman RE, Vaughan VC, eds. Nelson textbook of pediatrics. Philadelphia: WB Saunders, 1983:1394.

7 Royal College of General Practitioners and British Paediatric Association. Guideline for the training and accreditation of eneral practitioner in child health surveillance. London: BPA, December, 1985 .

8 Committee on Health Promotion, Faculty of Community Medicine of the Royal College of Physicians of the United Kindom. Guideline for health promotion. No 18 . London: March 1989.

9 Chilvers C, Dudley NE, Gough MH, Johnson MB, Pike MC Undescended testes: the effect of treatment on subsequen risk of subfertility and malignancy. $\mathcal{F}$ Pediatr Surg 1986;21 691-6.

10 Tamhne RL, Jarvis SN, Waterston AJR. Auditing com munity screening for undescended testes. Arch Dis Child 1990;65:888-90.

11 Cooper BJ, Little TM. Orchidopexy: theory and practice. BMF 1985;291:705-7.

12 Boggis ARJ, Rowlatt RJ. A study of sources of delay in diagnosis and treatment of undescended testicle. $\mathcal{F} R \mathrm{Coll}$ Gen Pract 1989;34:440-6.

13 Richman S, Miles M. Selective medical examinations for school entrants: the way forward. Arch Dis Child 1990;65: $1177-81$. 